\title{
DO NATURAL DISASTERS INCREASE FINANCIAL RISKS? AN EMPIRICAL ANALYSIS
}

\author{
Chun-Ping Chang* and Wan-Li Zhang** \\ * Department of Marketing Management, Shih Chien University, Kaohsiung, Taiwan. \\ Email: cpchang@g2.usc.edu.tw \\ ${ }^{*}$ Corresponding Author. School of Economics and Finance, Xian Jiaotong University, Xian, Shaanxi, China. \\ Email: zhangwanli623@163.com
}

\begin{abstract}
Using an unbalanced panel data consisting of deaths from natural disasters and five factors of financial risks in 136 countries, this paper analyzes the effect of natural disasters on different financial risks. The conclusions are as follows: (1) natural disasters lead to financial crisis by reducing GDP and trade and increasing domestic and foreign debt; (2) the effects of natural disasters on financial risks are dynamic and long term, with the effect weakening with time; and (3) the negative effects of natural disasters on financial risks in high-income and OECD countries are smaller than those of low-income and non-OECD countries.
\end{abstract}

Keywords: Natural disaster; Financial risks; Fixed effects model; Panel unit root test. JEL Classifications: E44; F30; O1; Q54.

Article history:

Received : July 15, 2019

Revised : October 20, 2019

Accepted : December 29, 2019

Available Online: January 2, 2020

https://doi.org/10.21098/bemp.v23vi0.1215 


\section{INTRODUCTION}

There is growing evidence that people's lives are affected by climate change, such as increases in temperature and sea levels, aggravated environmental pollution, and decreases in forest cover area (Kabisch et al., 2016). For these reasons, the quantity and severity of natural disasters worldwide are rapidly rising. A natural disaster can influence the economy, finance, and politics via loss of life and property (Mohan et al., 2018). Different natural disasters also have different impacts on financial risks, including foreign debt, exchange rate stability, international liquidity, and the current account. When a natural disaster strikes, central and regional governments must increase investments and subsidies to rebuild and help casualties (Ward et al., 2020). Among the least developed countries, foreign debt will increase, as will the current account with growing demand, due to a decline in crop production. For countries with little land area and poverty problems, natural disasters can even cause civil war and disturbances, which can lead to a decline in exchange rates (Abarcar, 2017; Klomp, 2017). Organisation for Economic Cooperation and Development (OECD) countries can obtain assistance from member countries, which can help alleviate financial risks. In this regard, knowledge of the way a natural disaster affects financial risks is necessary. Whether a natural disaster has different influences on financial risks, given heterogeneity across countries, is also significant knowledge.

For instance, hurricane season creates problems for coastal countries, such as Jamaica and Grenada. According to Heger et al. (2008), hurricane losses reached almost US\$3.1 billion in 2004, which is $10 \%$ of the Gross Domestic Product (GDP) of Jamaica and $200 \%$ of the GDP of Grenada. Such losses have forced the government of Grenada to provide fewer subsidies to its inhabitants. Such a decline in living standards will reduce both savings and investments, which is not conducive to the development of financial sectors, and financial risks will thus increase. The International Monetary Fund (IMF, 2003) has concluded that the damage caused by natural disasters contributes 3\% of the fiscal deficit in Africa (Strobl, 2012). The December 2004 Indian Ocean tsunami and Cyclone Nargis, which hit Myanmar in May 2008, also catastrophically damaged local economic and financial development (Barthel and Neumayer, 2012). These instances show how natural disasters have a strong influence on financial risks, with diverse effects for different countries.

How, then, do natural disasters affect financial risks? Why are there such big gaps in financial risks between different regions? To explain these issues, we must analyze the factors of the financial risks and consider different national characteristics. According to the International Country Risk Guide (ICRG), financial risks can be divided into five categories (Bayoumi et al., 2015).

First, it is obvious that earthquakes and tsunamis are the most influential natural disasters, since they both result in high mortality rates and severe building damage. Such destruction is catastrophic for small countries and can even destroy whole cities, which the country must rebuild by investing more money. However, the source of reconstruction funds is the national revenue and debt from other countries. National foreign debt thus increases and the countries will be unable to pay the debt service (Skoufias, 2003; Ouattara and Strobl, 2013). Second, although storms, flooding, and drought will not cause as many deaths or losses of homes, they will harm crops and their harvest. The GDP and exports will 
decrease dramatically, especially for developing countries which depend mainly on agriculture, and the current account deficit will rise and result in exchange rate instability and depreciation of the national currency (Kilby, 2009; Baur et al., 2018). Third, heavy losses force countries to use foreign exchange reserves, which maintain exchange rate stability, to adjust the balance of payments and international liquidity. If the loss, as a percentage of the GDP, is small, however, the country will not need to use foreign exchange reserves. When a natural disaster strikes, OECD members will also help each other via humanitarian assistance, financial rescue, and rescue materials (Toya and Skidmore, 2007; Yamamura, 2014). This will reduce foreign debt and the current account, helping avoid financial risks. Overall, the evidence suggests that natural disasters have different effects on financial risks in countries of different economic levels. The relations also vary between OECD and non-OECD countries.

The objectives of this paper are twofold. The first objective is to collect data on natural disasters from EM-DAT, the international disasters database, and to recalculate the losses of natural disasters, to verify their impact on financial risks. Some of the literature studies only the effect of specific natural disasters on economic conditions (Jonkman and Kelman, 2005; Barone and Mocetti, 2014). However, there are many types of natural disasters, such as earthquakes, floods, landslides, storms, epidemics, and tsunamis. All of these will affect financial risks, and the adoption of data on a specific natural disaster will significantly underestimate the impacts (Cassar et al., 2017).

This paper thus calculates the sum of the deaths from total natural disasters for different countries every year to study the relation between deaths caused by natural disasters and different financial risks. We also use the number of natural disasters as a control variable to measure the frequency of disasters. Many studies only analyze how natural disasters affect the exchange rate and foreign debt (Gourio, 2013; Farhi and Gabaix, 2015). Ebeke and Combes (2013) also use lagged measures of natural disasters to study their effect on output growth volatility. They find natural disasters to have a sustained influence. Generally speaking, our research studies the dynamic effects of the total damage of natural disasters on different financial risks. We conclude that the total death count has a negative effect on all financial risks.

The second major objective of this paper is to explore the effect of natural disasters on financial risks among OECD countries and countries with different income levels. Earthquakes and tsunamis have a stronger influence on trade in coastal countries, such as Japan and Korea. Such disasters decrease exports and imports affecting global supply chains. OECD members will assist an OECD country that has suffered a disaster. If the losses as a percentage of the GDP are not large, the economy could return to normal within weeks, with financial risks gradually returning to stability (Schettkat, 2010; Waldenberger, 2013). The negative relation between natural disasters and financial risks in OECD countries could be smaller than in non-OECD countries. Kellenberg and Mobarak (2008) propose that rising incomes will reduce the impact of natural disasters. Raddatz (2007) points out that natural disasters have a short-run impact on economics. Middle-income countries undergo a big impact and need a long time to recover. Kim (2012) finds that, in the 21st century, people in poor countries are twice as exposed to natural disasters 
than in high-income countries. Countries with different income levels suffer from different levels of damage from natural disasters, and natural disasters also have diverse impacts on financial risks. Therefore, this article divides countries into two subsamples, namely, countries categorized by income level (high- and lowincome countries) and countries categorized by whether they are OECD members or not, to analyze the different dynamic relations.

Summarizing the abovementioned literature, there are many studies on the impacts of different natural disasters and how they affect politics and economics. However, very few studies have focused on the relation between natural disasters and financial risks. Moreover, the dynamic relation between natural disasters and financial risks is seldom considered together with heterogeneity across countries. In addition, this paper makes three contributions to the literature, as follows. (1) Unlike other research on the effects of natural disaster on financial risks, our work focuses on financial risks along the following five dimensions: total foreign debt, debt service, the current account, international liquidity, and exchange rate stability. This method allows us to understand the total influence of natural disasters on different financial risks. (2) We split the full sample into two subsamples based on OECD membership and income levels according to the World Bank's classification. We test whether low-income and non-OECD countries face more severe financial risks (Raddatz, 2007; Hallegatte et al., 2013). (3) The previous literature has found that natural disasters have long-term effects. Nevertheless, there is little research that investigates the relation between natural disasters and financial risks with regard to time effects and heterogeneity across countries simultaneously (Berrebi and Ostwald, 2013; Toya and Skidmore, 2014). This paper studies the dynamic effect of natural disasters on different financial risks together with consideration of OECD membership and income levels.

The remainder of the paper is organized as follows. Section II presents the data and methodology. Section III shows the parameter estimation based on panel fixed effects regression and analyzes the results considering OECD membership and different income levels. Finally, Section IV summarizes the results and offers policy suggestions.

\section{DATA DESCRIPTION AND METHOD}

\section{A. Methodology}

To test whether natural disasters affect financial risks, we first use the following empirical framework:

$$
\operatorname{Risk}_{i t}^{m}=C+\beta \times N d d_{i t}+\gamma \times N d n_{i t}+\delta^{\prime} X_{i t}+\mu_{i}+\xi_{t}+\varepsilon_{i t}
$$

where Risk $_{i t}^{m}$, the main dependent variable, represents the different financial risks; $N d d_{i t}$ is the independent variable, proxied by the total number of death due to natural disasters; $N d n_{i t}$ stands for the number of natural disasters; and $X_{i t}$ represents the control variables. In Equation (1), $\mu_{i}$ captures the individual countries' fixed effects, $\xi_{t}$ captures time fixed effects, the term $\varepsilon_{i t}$ is the residual of the model, and $m=1,2,3,4,5$ indicates the five types of financial risks, with $t=1,2, \ldots, \mathrm{T}$ periods and 
$i=1,2, \ldots, \mathrm{N}$ panel members. This paper uses panel fixed effects regression to estimate the parameters.

In Equation (1), $\beta$, which is the coefficient of $N d d_{i t}$, shows the magnitude of the effect of natural disasters on financial risks. The role of $N d d_{i t}$ is to illustrate how the frequency of natural disasters affects finance. It is generally accepted that a country with a large area and high population density can be subject to serious damage from a natural disaster. Hence, this paper uses the frequency of natural disasters. Miao and Popp (2014) point out that natural disasters have a long-term impact on economics. We therefore add the lagged terms of natural disasters into the equation and obtain the following new model:

$$
\operatorname{Risk}_{i t}^{m}=C+\beta_{l} \times N d d_{i t, l}+\gamma_{l} \times N d n_{i t, l}+\delta^{\prime} X_{i t}+\mu_{i}+\xi_{t}+\varepsilon_{i t}
$$

where $l=0,1,2$ represents the lagged rank of the independent variable, $\beta_{0}$ represents the effect of a natural disaster on current financial risks, and $\beta_{1}$ and $\beta_{2}$ indicate whether current financial risks are influenced by natural disasters in the two previous years. This model considers the dynamic effects of natural disasters and provides a better explanation than static panel model.

\section{B. Data Set}

\section{B.1. Dependent Variables}

This paper analyzes how natural disasters affect different financial risks. We categorize the financial risks, as the dependent variables, into the five following factors, according to the ICRG classification (Byoun and $\mathrm{Xu}, 2014$; Chiu and Lee, 2019).

(1) Total foreign debt (Risk1). This variable is measured by the ratio of gross foreign debt to the gross domestic product, where all terms are converted into US dollars at the average exchange rate for that year. The values range from zero to 10. The country faces less serious financial risks when total foreign debt increases.

(2) Debt service (Risk2). This variable is assessed by foreign debt service as the percentage of total exports of goods and services, where all terms are converted into US dollars at the average exchange rate for that year. The values range from zero to 10. As debt service increases, financial risks gradually decrease.

(3) Exchange rate stability (Risk3). This variable is calculated by the value of the appreciation or depreciation of the currency against the US dollar (against the euro in the case of the United States) over a 12-month period. The value ranges from zero to 10. Its implication is the same as debt service's (Risk2), namely, that financial risks increase if the exchange rate stability decreases.

(4) Current account (Risk4). This variable is measured by the ratio of the balance of payments to the sum of the total exports of goods and services, where both terms are converted into US dollars. The magnitude of this variable ranges from zero to 15. Financial risks decrease with the increasing value of the current account.

(5) International liquidity (Risk5). This variable is assessed by the proportion of official holdings of gold to the average monthly merchandise import cost, where 
both terms are converted into US dollars. It should be noted that this index excludes IMF credits and the foreign liabilities of the monetary authorities. It provides a comparative liquidity risk ratio that indicates how many months of imports can be financed with reserves. The index ranges from zero to five. The greater the value of international liquidity, the smaller the financial risks.

\section{B.2. Independent Variables}

This paper uses the impact of natural disasters as the independent variable, namely, the number of deaths from disasters and the total number of persons affected, to study the relation between natural disasters and financial risks. To control for the influence of natural disasters' frequency and distinguish large disasters from small ones, we use an index for the number of disasters every year (Visser et al., 2014; Ward and Shively, 2017). Generally speaking, Ndd, Nde, and $\mathrm{Ndn}$ are the logarithms of the numbers of deaths, the total number of persons affected, and the number of disasters, respectively. We also use one- and twoperiod lags of the three independent variables to analyze the dynamics. We use $N d d$ in the basic model and Nde in a robustness test and find they all have negative effects on financial risks. The types of natural disasters are obtained from EM-DAT and include droughts, earthquakes, epidemics, extreme temperatures, storms, landslides, floods, and volcanic eruptions. These indicators directly reflect the severity of natural disasters.

\section{B.3. Control Variables}

An additional issue is the role of other variables, which can influence financial risks. This paper controls for all such variables, as follows. (1) We use the GDP per capital $(P g d p)$ to measure the national income per capita, converted into US dollars. Countries with a high income level generally have a more mature financial market and well-appointed infrastructure, which helps to reduce financial risks and avoid damage from natural disasters (Cavallo et al., 2013; Robinson et al., 2017). (2) We use net inflows of foreign direct investment $(F D I)$, measured by the ratio of net inflows of foreign direct investment to the GDP, with all terms converted into US dollars. A higher FDI value indicates better development in the country, along with a higher GDP, a more skilled labor force, and so forth, all of which reduce financial risks (Hoshi, 2018; Pek et al., 2018). (3) Following Niepmann and Schmidt-Eisenlohr (2017), we use the ratio of imports and exports of goods and services to the GDP (Trade), converted into US dollars, to measure trade levels (Laseen et al., 2017). (4) Song et al. (2018) point out that the uncertainty of research and development (R\&D) requires strong financial support and low financial risk. Improper R\&D expenditures will increase financial industrial business risk, financing risks and so on, throughout innovation failure and financing failure. We use the percentage of R\&D expenditures to the GDP $(R \mathcal{E} D)$, following Li et al. (2019). (5) The ratio of the central government's debt to the GDP $(G d)$ is used to measure a country's debt level. Excessive government debt will increase pressure on the payments of financial institutions and enterprises (Liang et al., 2017). Note that foreign debt differs from central government debt. (6) We also follow Eckstein et al. (2019), 
who conclude that financial risks increase when the unemployment rate rises. We thus use the ratio of unemployment to the total labor force (Unem) to assess the level of unemployment (Hall, 2017). (7) Zhang et al. (2016) indicate that the rapid expansion of manufacturers will exacerbate the misallocation of resources and lead to an unbalanced industrial structure, further exposing the whole economic sector to high risks. The industrial structure is thus introduced into the model and is calculated as value-added manufacturing to the value added of agriculture (Is). (8) It is obvious that inflation is the main instrument of monetary policy for controlling the economy (Fouejieu, 2017). However, unsuitable monetary policy will lead to a high inflation rate, as well as depreciation of the local currency. National consumption will then surge, which will lead to high unemployment due to depreciation. The increasing foreign debt and unstable exchange rate will all increase financial risks. Hence, this paper adopts an inflation rate that considers a GDP deflator (IR). (9) The exchange rate, as a unit of measure of the national currency, can reflect national development. The exchange rate's depreciation means the local currency is losing value, and residents will increase their investment in foreign exchange and fixed assets, increasing financial risks as well. We introduce the exchange rate (Er) into the model, following Reboredo et al. (2016). (10) Income inequality implies improper income distributions, industrial structures, and financing policies. Such lack of suitability will cause different levels of demand for imports and exports, which will affect the flow of international capital irrationally, as trade surplus or deficit will grow too large. Therefore, this paper utilizes the Gini index (Gini) to represent income inequality (Chiu and Lee, 2019).

\section{Descriptive Statistics}

First, we introduce the source of the data for this paper. The data on natural disasters are from EMDAT. The source of the financial risk data is ICRG. The data for the control variables are from World Bank Open Data. All the variables cover from 1984 to 2017, except Risk3, which ranges from 1984 to 2013. The sample is an unbalanced panel, since we delete missing values. World Bank Open Data divides countries into four categories: low income, lower middle income, upper middle income, and high income. In this paper, upper-middle-income and high-income countries are categorized as high-income countries. Low-income and lowermiddle-income countries are categorized as low-income countries. Where are 136 countries in the sample, including 29 OECD and 107 non-OECD countries, with 88 high-income countries and 48 low-income countries.

The trends for $N d d$ and different financial risks are plotted in Figure 1. Note that Ndd and financial risks have opposite trends, suggesting a potentially negative relation between deaths due to natural disasters and different financial risks. Table 1 shows the descriptive statistics for the variables in the 136 sample countries, revealing means for Risk1, Risk2, Risk3, Risk4, and Risk5 of 7.951, 5.859, $6.743,11.009$, and 1.886, respectively. We find that the mean of Risk5 is the smallest, which indicates the highest financial risk. There are 3,731 observations for Risk3 from 1984 to 2013. The standard deviations of all the dependent variables are small, showing little fluctuation among the financial risks. We note that the means of $N d d$ and $N d n$ are 1.507 and 1.557 , respectively, which indicates that natural disasters 
are relatively severe. The standard deviations of $N d d$ and $N d n$ are also small, meaning that the numbers of disasters and resulting deaths vary only slightly. Finally, the standard deviations of the control variables are small, indicating that these variables have inconspicuous fluctuations and that there are differences between the variables, except for Gd, Ir, Is, Unem, and Gini.

Figure 1.

\section{Natural Disasters and Different Risks in the World (1984-2017)}

This figure shows the relationship between the death from natural disasters (Ndd) and different risks in the world (1984-2017). Ndd is the logarithm of the national average death from natural disasters. Risk 1 to Risk 5 are the logarithms of different financial risks.

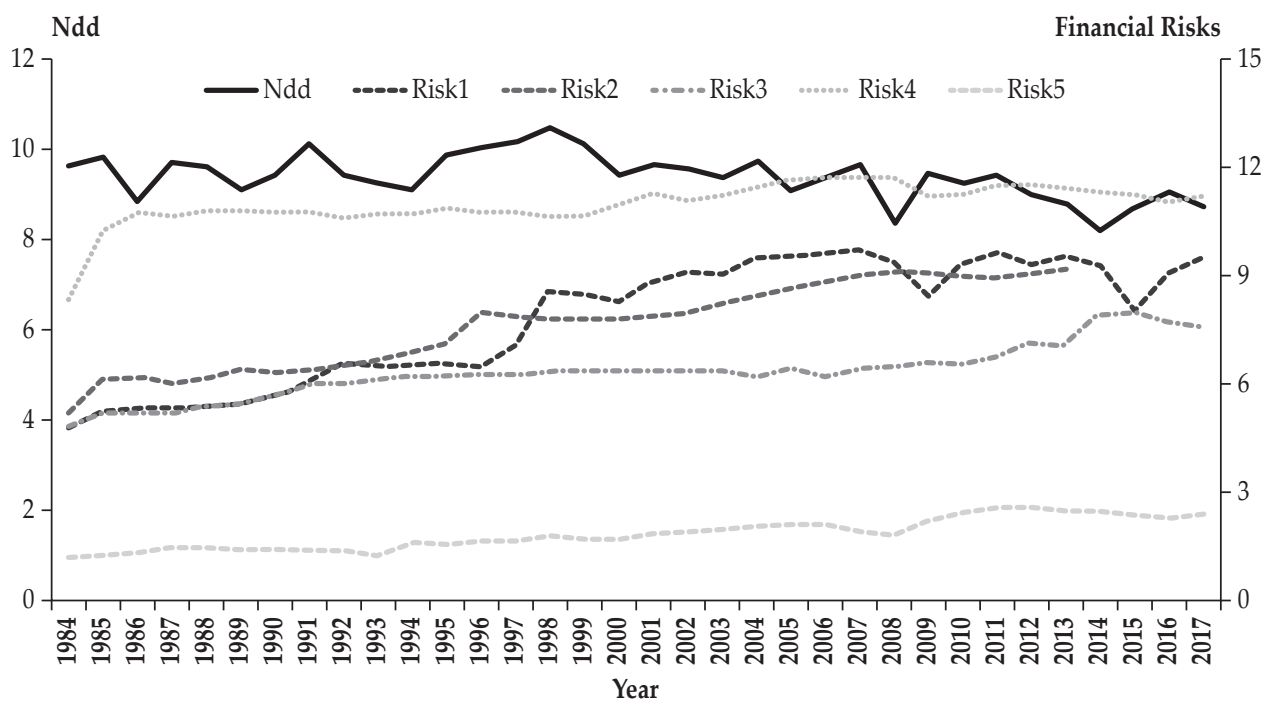

Table 1.

\section{Summary Statistics}

This table reports the summary statistics of the variables in our research, which is obtained using STATA 15. Column 1 has variable name. "N" in column 2 represents the total number of observations. "Mean", "Std. Dev", "Minimum", "Maximum" and "Median" denote the descriptive statistics.

\begin{tabular}{lcccccc}
\hline Variable & N & Mean & Std. Dev & Minimum & Maximum & Median \\
\hline Risk1 & 4275 & 7.951 & 2.328 & 1.083 & 10.000 & 9.000 \\
Risk2 & 4275 & 5.859 & 2.410 & 0.000 & 10.000 & 6.000 \\
Risk3 & 3731 & 6.743 & 3.364 & 0.000 & 10.000 & 8.000 \\
Risk4 & 4275 & 11.009 & 2.451 & 0.000 & 15.000 & 11.5 \\
Risk5 & 4275 & 1.886 & 1.493 & 0.000 & 5.000 & 1.792 \\
Ndd & 4275 & 1.507 & 2.228 & 0.000 & 8.113 & 0.000 \\
Ndn & 4275 & 1.557 & 2.459 & 0.000 & 14.000 & 1.000 \\
Pgdp & 4275 & 1.042 & 1.485 & 0.251 & 6.965 & 0.366 \\
FDI & 4275 & 0.033 & 0.055 & 0.000 & 0.361 & 0.174 \\
Trade & 4275 & 3.912 & 1.225 & 0.123 & 5.797 & 4.162 \\
R\&D & 4275 & 0.383 & 0.749 & 0.021 & 3.340 & 0.121 \\
\hline
\end{tabular}


Table 1.

Summary Statistics (Continued)

\begin{tabular}{lcccccc}
\hline Variable & $\mathbf{N}$ & Mean & Std. Dev & Minimum & Maximum & Median \\
\hline Gd & 4275 & 11.954 & 27.098 & 1.792 & 129.874 & 2.165 \\
Unem & 4275 & 6.370 & 5.547 & 2.143 & 24.439 & 5.280 \\
Is & 4275 & 4.319 & 9.886 & 0.458 & 75.452 & 1.438 \\
Ir & 4275 & 13.153 & 34.103 & -12.994 & 276.754 & 4.789 \\
Ex & 4275 & 0.039 & 0.146 & 0.001 & 1.103 & 0.006 \\
Gini & 4275 & 11.428 & 18.595 & 0.001 & 58.100 & 0.125 \\
\hline
\end{tabular}

\section{EMPIRICAL RESULTS}

A. Unit Root Test

Since the time span of our sample is relatively long, we first conduct a panel unit root test to ensure the robustness of the empirical results. We use a Fisher test to check the unit root, given the unbalanced panel of sample data (Fang and Chang, 2016). The unit root test assumes separate cross sections (Sadorsky, 2014). Pesaran (2007) indicates that the unit root test will be invalid with significant deviations as long as panel data correlation exists among the cross-sectional data. Therefore, we conduct a cross-sectional dependence test, following Pesaran (2007) and Wei et al. (2019). We also remove the means of cross-sectional units before running a Fisher test. Table 2 shows the final results. It is obvious that the cross-sectional dependence tests of all the variables can be significantly rejected at the $1 \%$ level, revealing cross-sectional correlation. Therefore, the panel unit test is valid. The panel unit root test and second panel unit root test results show that all the variables, except for $E x$, are rejected at the 1\% level. Therefore, there is no unit root.

Table 2.

Cross-Section Correlation Test and Panel Unit Root Test

This table shows the cross-section correlation test and panel unit root test for all variables. These tests are performed by using STATA 15. The CD-test follows the research of Wei et al. (2019) and the original hypothesis is that there exists a cross-section correlation. The fisher-test follows the research of Fang and Chang (2016) and the original hypothesis is that there exists panel unit root.

\begin{tabular}{lcccccc}
\hline \multirow{2}{*}{ Variable } & \multicolumn{2}{c}{ Cross-section correlation } & \multicolumn{2}{c}{ Panel unit root } & \multicolumn{2}{c}{ Second Panel unit root } \\
\cline { 2 - 7 } & CD-test & $\boldsymbol{p}$-value & Fisher-test & $\boldsymbol{p}$-value & CIPS-test & $\boldsymbol{p}$-value \\
\hline Risk1 & 275.009 & 0.00 & 50.379 & 0.00 & -4.155 & 0.00 \\
Risk2 & 23.366 & 0.00 & 24.538 & 0.00 & -4.356 & 0.00 \\
Risk3 & 420.638 & 0.00 & 40.508 & 0.00 & -3.956 & 0.00 \\
Risk4 & 43.508 & 0.00 & 50.128 & 0.00 & -1.765 & 0.01 \\
Risk5 & 60.808 & 0.00 & 30.199 & 0.00 & -1.903 & 0.00 \\
Ndd & 16.509 & 0.00 & 57.432 & 0.00 & -2.139 & 0.00 \\
Ndn & 37.29 & 0.00 & 51.999 & 0.00 & -4.361 & 0.00 \\
Pgdp & 418.898 & 0.00 & 16.951 & 0.00 & -2.404 & 0.00 \\
FDI & 106.621 & 0.00 & 24.905 & 0.00 & -3.132 & 0.00 \\
Trade & 126.527 & 0.00 & 30.048 & 0.00 & -2.928 & 0.00 \\
R\&D & 113.801 & 0.00 & 30.703 & 0.00 & -4.606 & 0.00 \\
\hline
\end{tabular}


Table 2.

Cross-Section Correlation Test and Panel Unit Root Test (Continued)

\begin{tabular}{lcccccc}
\hline \multirow{2}{*}{ Variable } & \multicolumn{2}{c}{ Cross-section correlation } & \multicolumn{2}{c}{ Panel unit root } & \multicolumn{2}{c}{ Second Panel unit root } \\
\cline { 2 - 7 } & CD-test & $p$-value & Fisher-test & $p$-value & CIPS-test & $p$-value \\
\hline Gd & 24.759 & 0.00 & 31.703 & 0.00 & -1.988 & 0.00 \\
Unem & 291.955 & 0.00 & 31.191 & 0.00 & -2.803 & 0.00 \\
Is & 122.835 & 0.00 & 27.099 & 0.00 & -3.056 & 0.00 \\
Ir & 81.843 & 0.00 & 44.475 & 0.00 & -3.406 & 0.00 \\
Ex & 155.973 & 0.00 & -1.328 & 0.90 & -4.001 & 0.00 \\
Gini & 54.466 & 0.00 & 61.887 & 0.00 & -5.045 & 0.00 \\
\hline
\end{tabular}

\section{B. Preliminary Analysis}

Table 3 displays the whole-sample estimation results for different financial risks. The coefficient of deaths from natural disasters $(N d d)$ is negative and significant at the $10 \%$ significance level for different financial risks. Column (2) shows that the coefficients of $N d d_{-1}$ and $N d d_{-2}$ are -0.051 and -0.015 , respectively, with t-test values of -2.35 and -1.21 . This result means that the effects of natural disaster on foreign debt (Risk1) gradually become weaker and nonsignificant over time. The parameters of $N d n$ are also negative and significant. Column (4) shows that $N d d$ has a negative influence on debt service (Risk2), and the lagged terms have the same impact. It is obvious that the role of natural disasters on debt service also weakens with time. However, the coefficients of $N d n$ are nonsignificant. The $N d d$ variable affects exchange rate stability (Risk3) negatively in column (6), but the lagged terms are not significant. The $N d n$ variable also has a negative effect on exchange rate stability. The impacts of $N d d$ and $N d n$ decrease simultaneously. From column (8), we obtain the same results, that the coefficient of $N d d$ on the current account (Risk4) is negative, with a nonsignificant t-test value of -1.87 . The first lag of $N d d$ has a negative but significant effect, which indicates that the effect of $N d d$ is decreasing. Meanwhile, $N d n$ has a nonsignificant negative influence on the current account. Finally, column (10) shows that the parameters of $N d d$ and its lagged terms are $-0.049,-0.039$, and -0.016 , respectively. There exists a negative impact on international liquidity (Risk5) to the $N d d$ that is gradually diminishing. Although the effects of $N d n$ and its lagged terms are nonsignificant, they are also negative. 


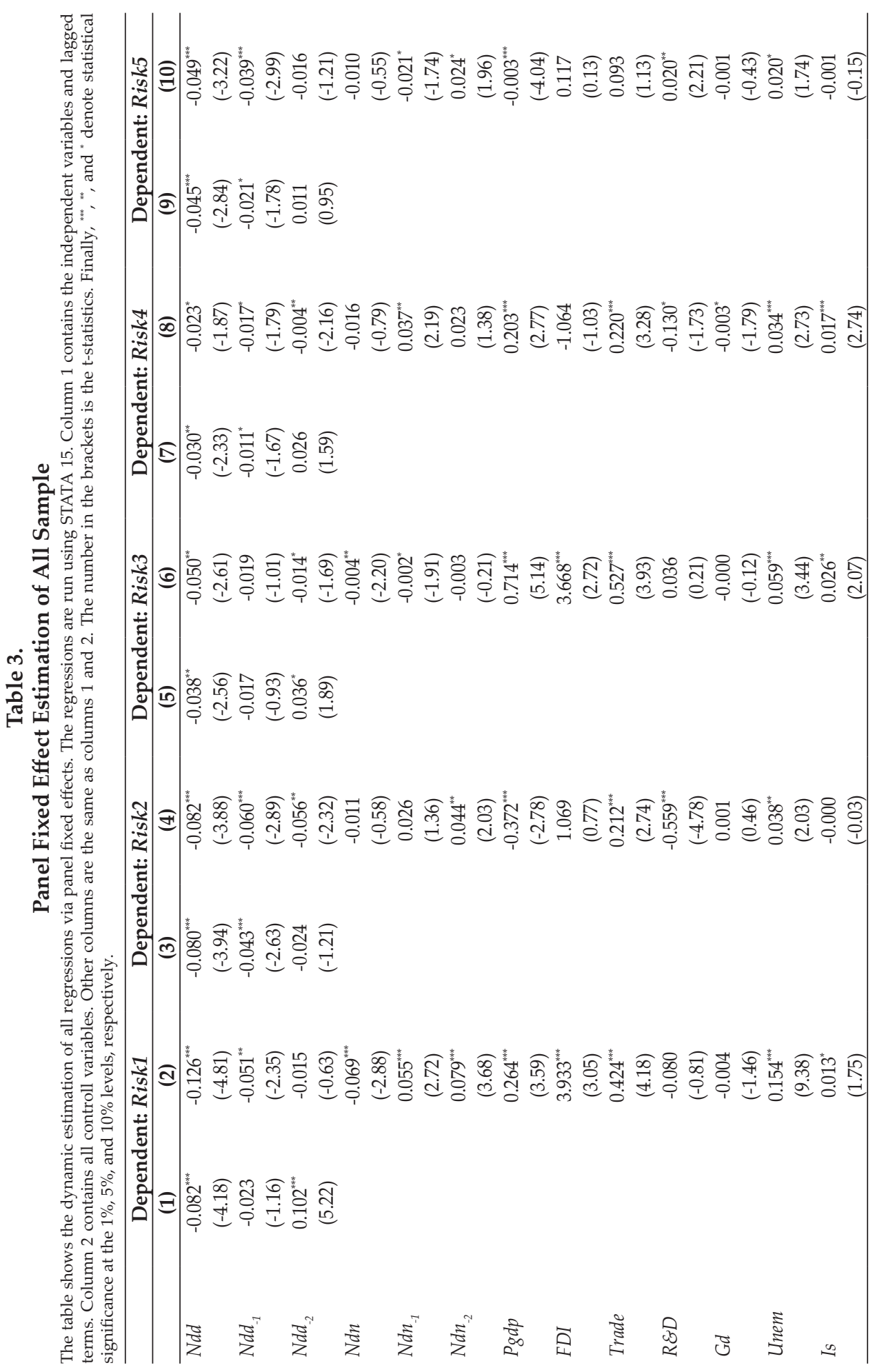


Summarizing the above-mentioned results, we find that natural disasters have a negative influence on different financial risks and the dynamic relations are long term, with diminishing effects over time. A high number of deaths means that a disaster has caused catastrophic harm to the country. If a center of economic development is hard hit by a natural disaster, an economic crisis can be caused, including unemployment, factory closures, and riots. The government will increase domestic and foreign debt to assist those affected, which also leads to a decline in national comparative advantages. Devaluation of the domestic currency will cause the outflow of foreign currency and R\&D, along with exchange rate instability. The country will also use foreign exchange reserves to promote local development and provide emergency assistance. In addition, natural disasters increase financial risks (Ajide and Raheem, 2016; Klomp, 2017). However, the living standards of the local residents and industrial development will gradually improve. along with the process that the country maintains to help affected areas. People will regain confidence in reconstruction, and the global chain will continue to recover. Generally speaking, trade, the local currency, and investment will gradually stabilize, leading to decreases in financial risks over time.

\section{Empirical Analysis of Heterogeneity \\ C.1. Classification by OECD and non-OECD Countries}

Table 4 shows the dynamic estimations for OECD and non-OECD countries. Almost all of the variables are negative at the $10 \%$ level of significance. First, the coefficients of deaths from natural disasters (Ndd) for OECD and non-OECD countries are -0.092 and -0.135 , respectively, with t-test values of -2.96 and -4.44 . This means that natural disasters have a negative effect on foreign debt (Risk1), and the influence in OECD countries is lower than that in non-OECD countries. Furthermore, the lagged terms are decreasing over time, and $N d n$ follows the same trend as $N d d$. Second, $N d d$ has a nonsignificantly negative relation with debt service (Risk2) among OECD members, but a significantly negative effect among non-OECD members. We arrive at the same conclusion, that the influence in OECD countries is smaller than in non-OECD countries, and the impact decreases gradually. Third, columns (5) and (6) indicate that the negative effect of Ndd on the exchange rate (Risk3) in OECD countries is also lower than in non-OECD countries, both with significant values. With time, the negative effect is gradually weakened. Fourth, the parameter of Ndd in OECD countries, in column (7), is -0.013 , while the value in column (8) is -0.029 . Both have a significant negative influence on the current account (Risk4). The trend of Ndd is the same as that of the other financial risks mentioned above. Finally, the coefficient of $N d d$ in OECD countries, namely, -0.036 , is obviously smaller than that in non-OECD countries, at -0.042 . The effects of natural disasters on international liquidity (Risk5) decrease over time in both OECD and non-OECD countries. Note that the parameters of the two lags of deaths from natural disasters are almost nonsignificant, revealing that natural disasters only affect financial risks in the current year and the next. 


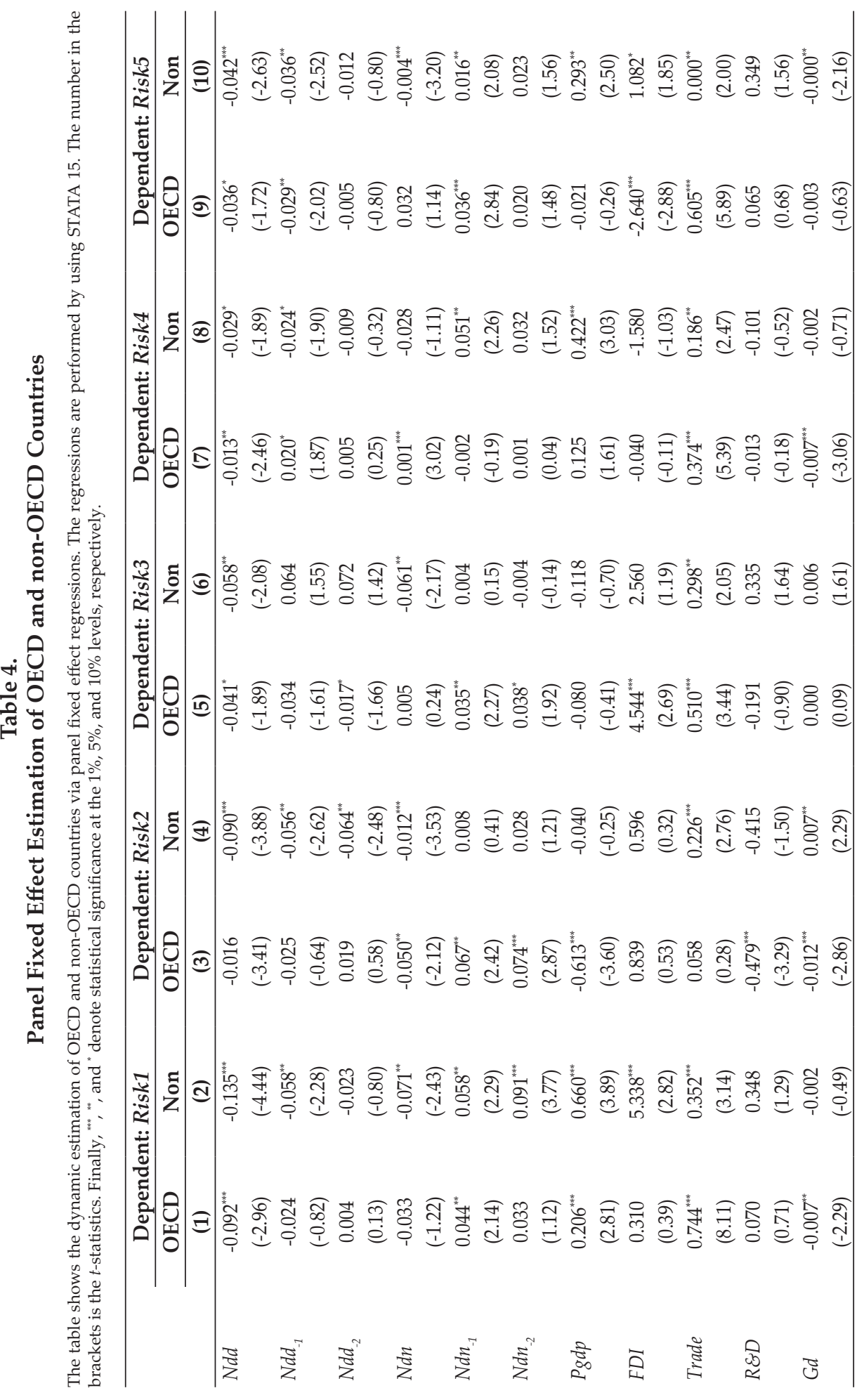




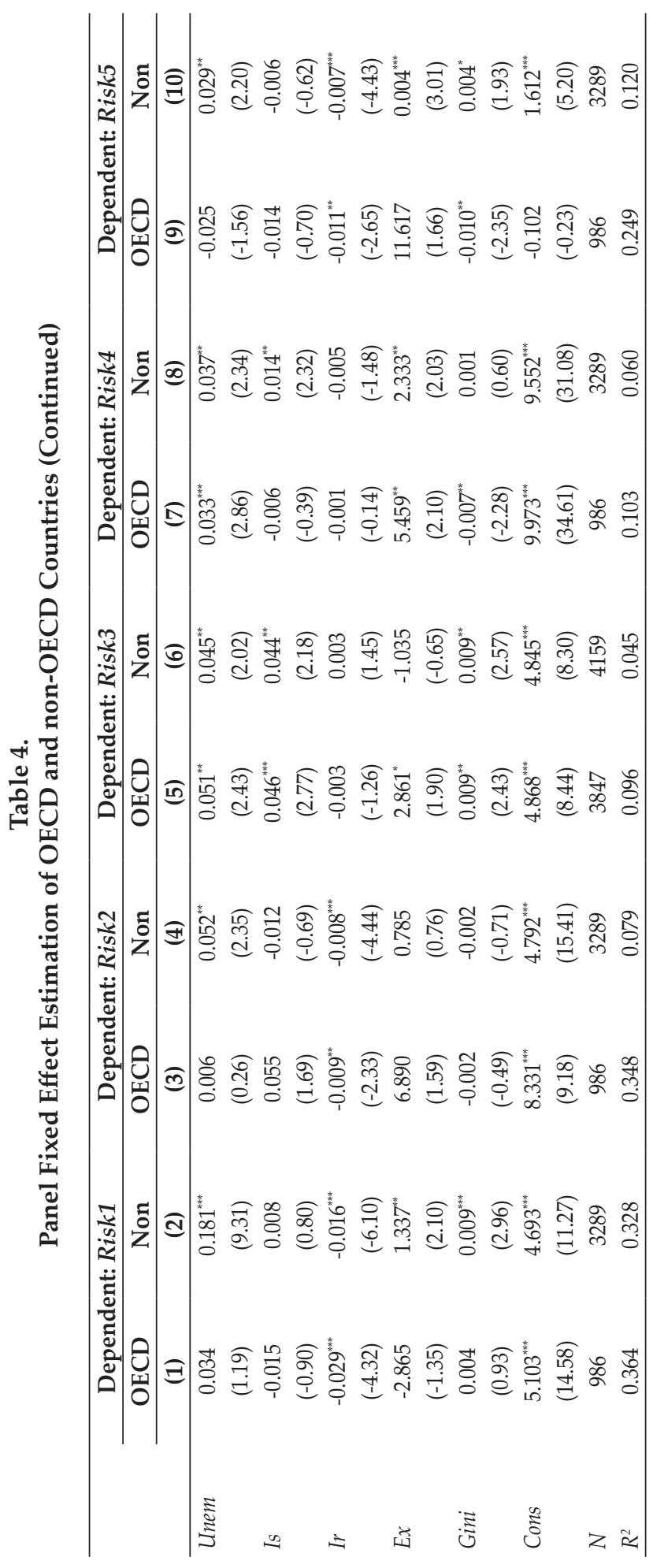


Why, then, are the effects in OECD countries weaker than those in nonOECD countries? The OECD is an international intergovernmental economic organization that aims to jointly address economic and social problems caused by globalization. Compared with non-OECD countries, there is closer cooperation among OECD countries, including trade, global chain, and R\&D activities. Sometimes one OECD country will require the products of other OECD members as intermediate input. Those OECD countries that suffer natural disasters will influence the development of other OECD countries. To obtain intermediate input and technology, other OECD countries will provide assistance to disaster-affected members. Although natural disasters can cause many deaths and great economic loss, an OECD country can recover quickly with the help of other members (Holm and Østergaard, 2015; Breckner et al., 2016). Levels of trade, exchange rates, and foreign exchange reserves will remain stable to maintain financial risks. Moreover, OECD countries have more advanced economic development than non-OECD countries, including their GDP, financial market, and technology. If the loss as a percentage of the GDP is relatively small, countries will be able to offset the impact of natural disasters through domestic financial expenditures and humanitarian assistance.

\section{C.2. World Bank Classification by Income}

Kellenberg and Mobarak (2008) have pointed out that rising income will decrease the risk of damage from natural disasters. In addition, people with a high income tend to gain access to better infrastructure, safer places to live, and so on. Natural disasters thus have less of an effect on people's lives, agriculture, and manufacture in countries with higher income levels. Therefore, this paper divides the whole sample into high- and low-income countries, following the World Bank's classification. Table 5 shows the results for countries of different income levels. We obtain the same conclusion, that natural disasters have a negative influence on different financial risks.

First, columns (1) and (2) in Table 5 show that the Ndd variable in high-income countries has a stronger negative effect on foreign debt (Risk1) than in low-income countries. The coefficients of $N d d$ are both significant, and the effect of $N d d$ decreases over time. Second, columns (3) and (4) show that the relations between $N d d$ and debt service (Risk2) are significantly negative, and the coefficients are -0.042 and -0.063 , respectively. Natural disasters reduce the value of Risk2 and the negative effects weaken with time. Third, the coefficients of death from natural disasters $(N d d)$ for low- and high-income countries in columns (5) and (6), respectively, are -0.021 and -0.043 , with t-test values of -1.76 and -2.01 . The first lags of $N d d$ in different types of countries are all significantly negative, but less than the current coefficients. Fourth, we also arrive at the same results for the current account (Risk4), that the parameters of $N d d$ are all negative. The effect decreases significantly for high-income countries, but nonsignificantly for lowincome countries. Finally, the relation between $N d d$ and international liquidity (Risk5) is the same as for other financial risks. The effects are significantly negative and weaken over time. 


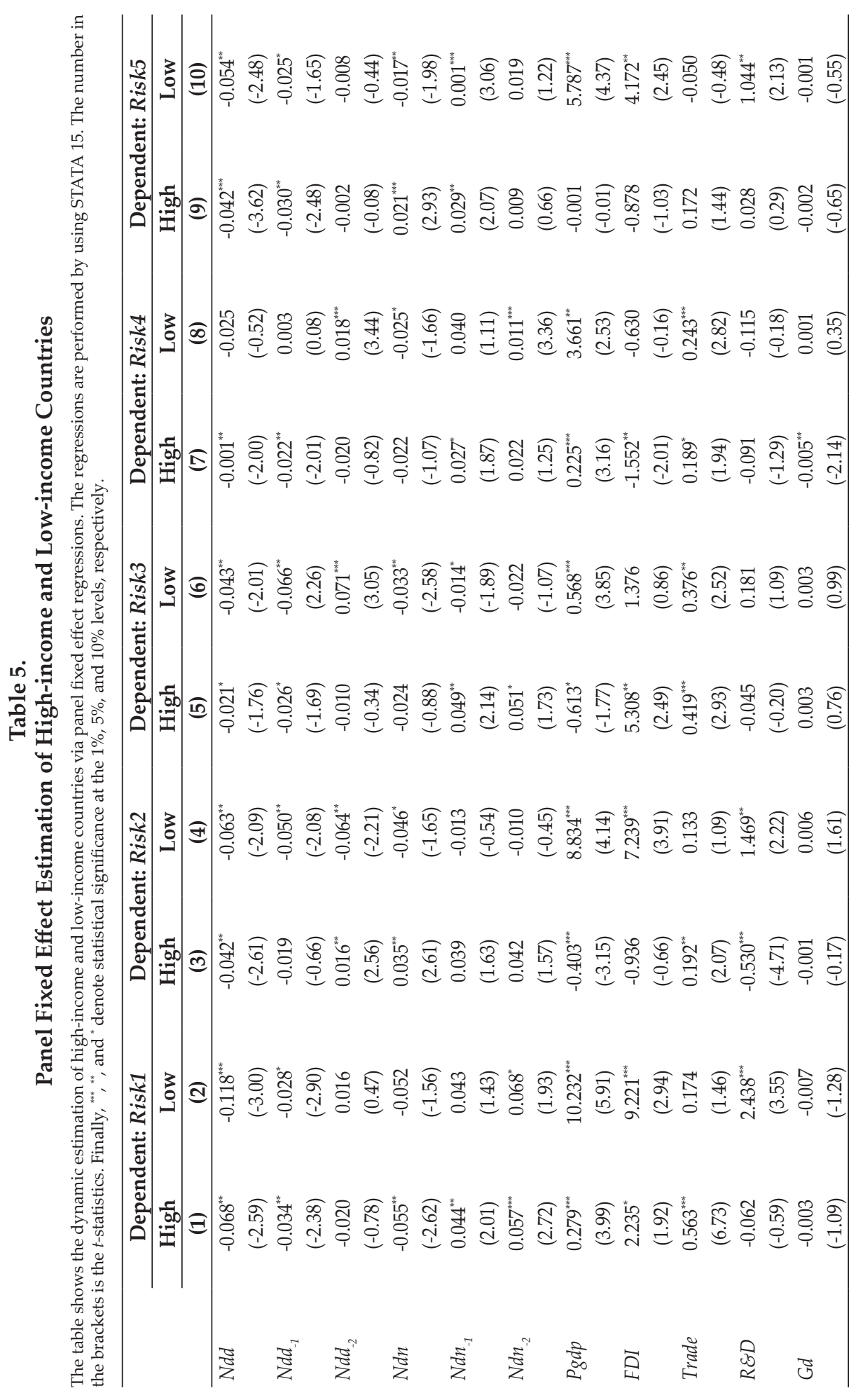




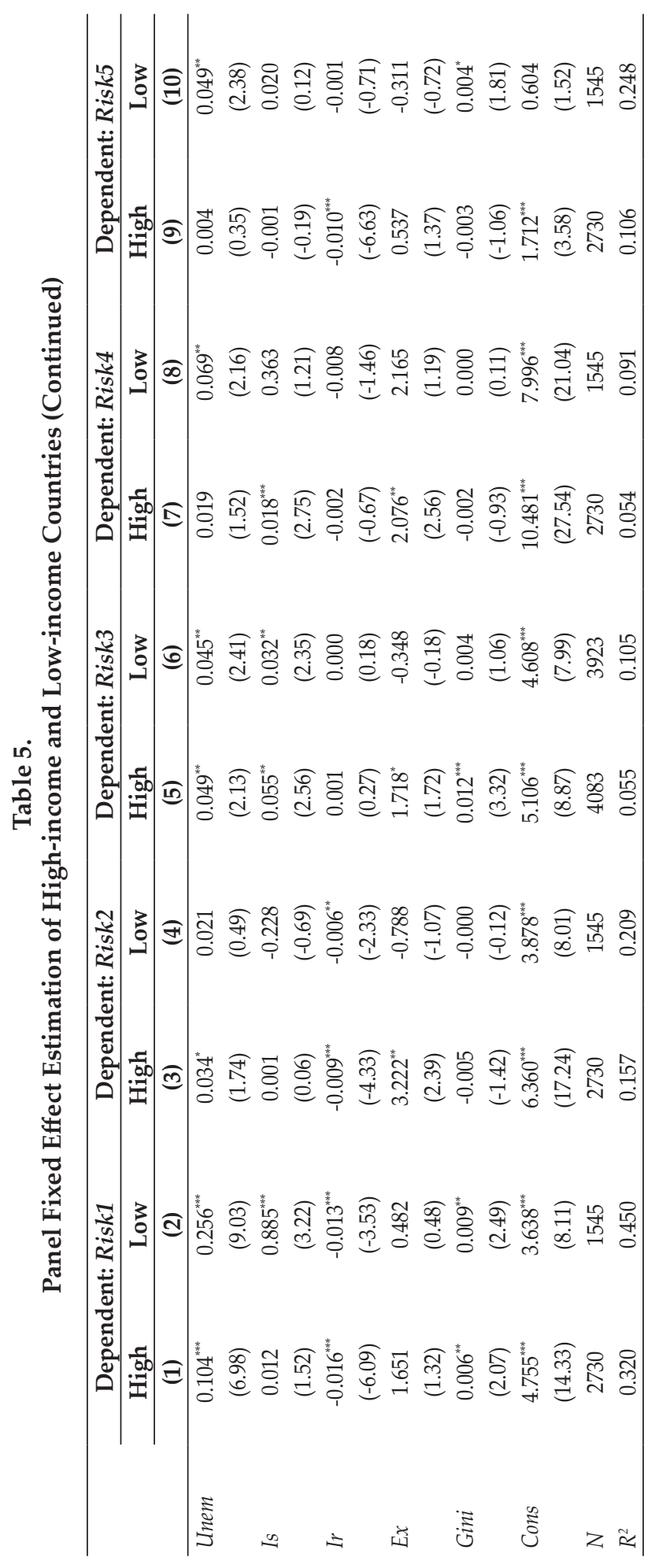


A country with a high income level means that it has high productivity, a good infrastructure, a complete global chain, and so on. Better infrastructure can reduce the deaths and losses due to natural disasters. A high income allows disasteraffected people to allocate more money to health care and reconstruction. Faster economic recovery can ensure the stability of the local currency, as well as the exchange rate. High-income countries also have high GDP and revenue levels, which can be used to recover the standard of living of those affected by the natural disaster and industry production. With adjustments to domestic industry, exports and imports will become stable again. The country only needs to use less foreign exchange reserves to address the effects of natural disasters, so that the exchange rate will not change much (Raddatz, 2005; Sawada and Takasaki, 2017). Moreover, high-income countries have greater productivity and a more complete global chain, which need to be closely linked to other countries. The production of these countries will be blocked if those countries that provide intermediate products and raw materials suffer a natural disaster. Other countries would also offer to assist disaster-influenced countries to restore normal domestic production levels. Generally speaking, high-income countries face lower financial risks compared with low-income countries.

\section{Robustness Tests}

Some insufficiencies in the analysis must be addressed. For example, is the independent variable of the number of deaths from a natural disaster suitable for our analysis? Is the traditional panel fixed effects estimation the most suitable model? Can we obtain the same results by using other, similar variables or measurements? Therefore, we use robustness tests to examine the results. Two robustness tests are adopted: (1) We utilize the total effect of natural disasters $(N d e)$ to replace the number of deaths from natural disasters $(N d d)$, and (2) we employ panel fixed effects estimation and consider a negative binomial to replace traditional panel fixed effects.

\section{D.1. A New Natural Disaster Index}

This paper first adopts Nde as the independent variable in the above analysis. Table 6 indicates that the empirical results are similar to those for $N d d$ as the independent variable. The results reveal that the t-test values of $N d e$ for different financial risks are mostly significant at the $10 \%$ level, and the coefficients of Nde are all negative. Moreover, the first and second lags of Nde in different models are almost negative and significant. These results all indicate significantly negative relations between natural disasters and financial risks, as well as hysteresis. We also find that the number of natural disasters has a dynamic influence on financial risks. These results are the same as in Table 3, which shows that the independent variable of $N d d$ is valid. 


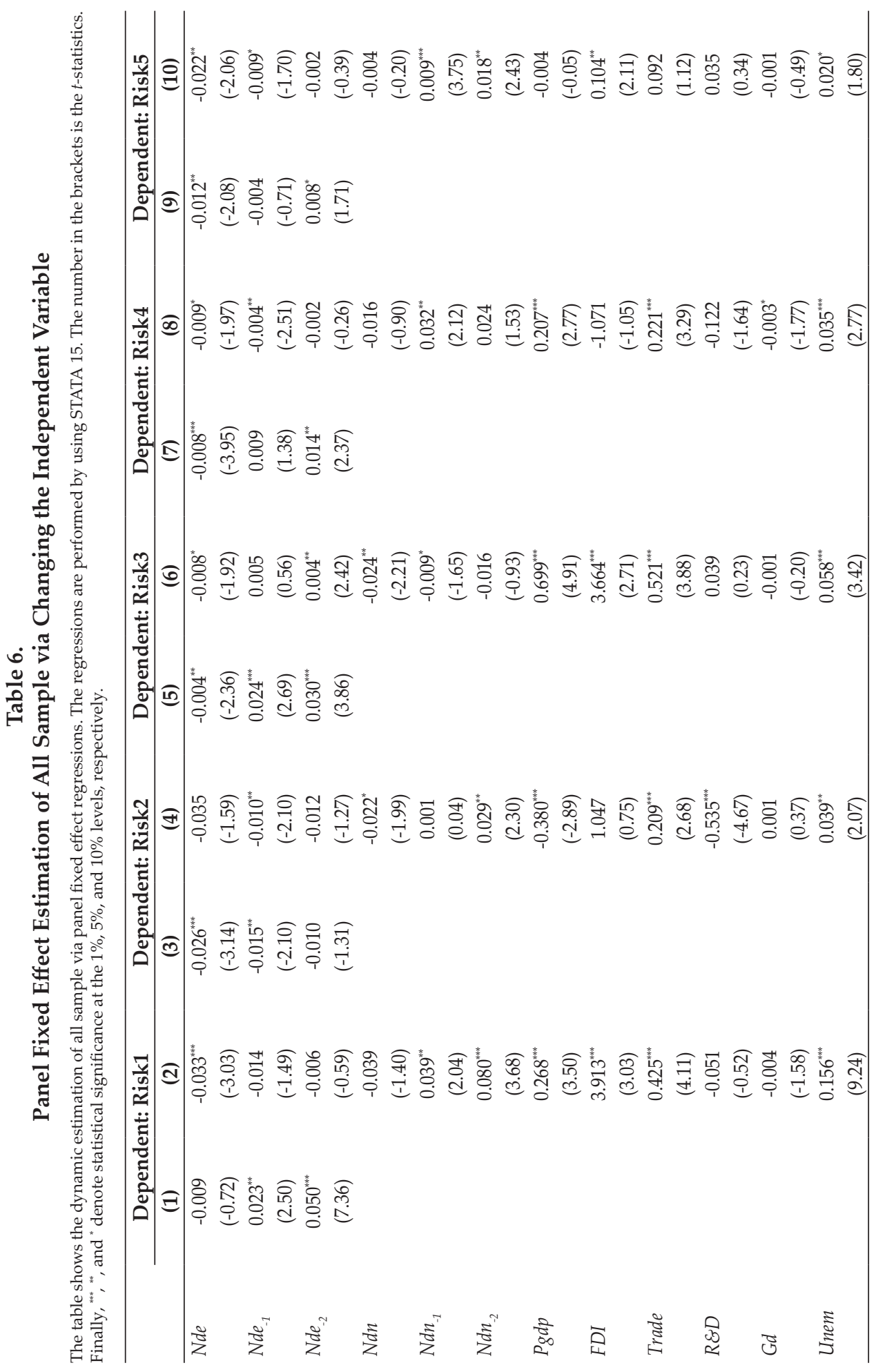




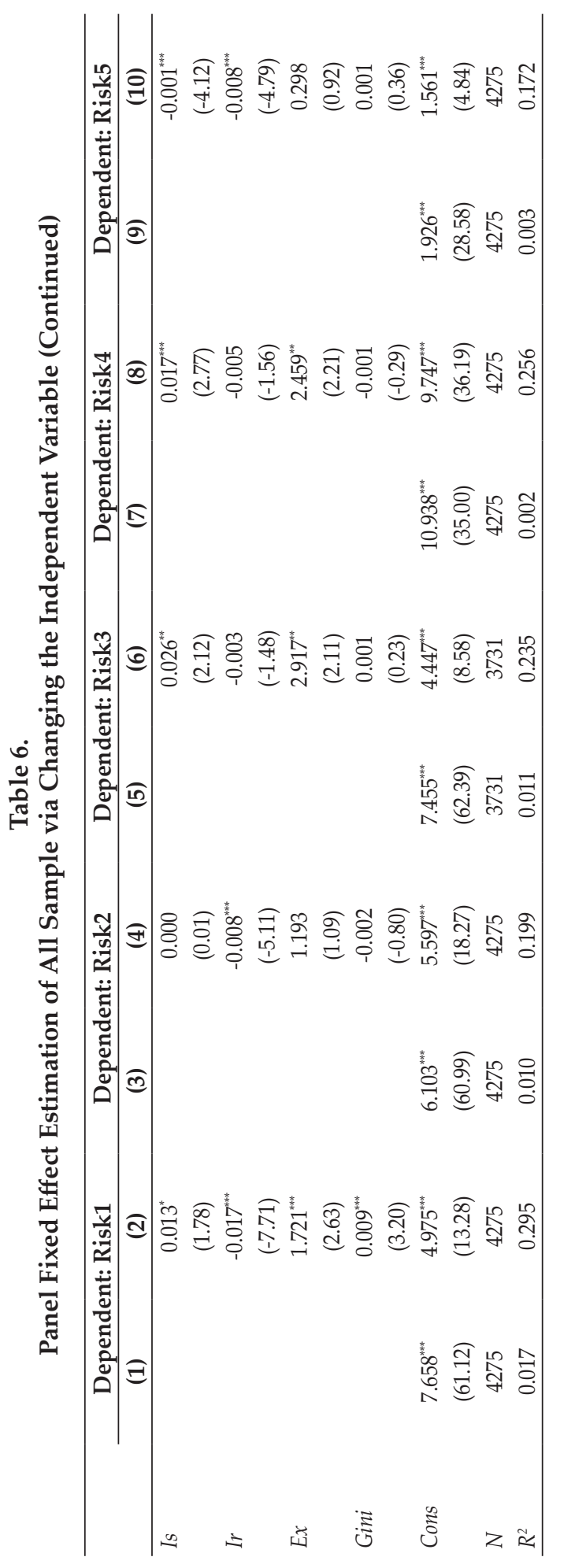




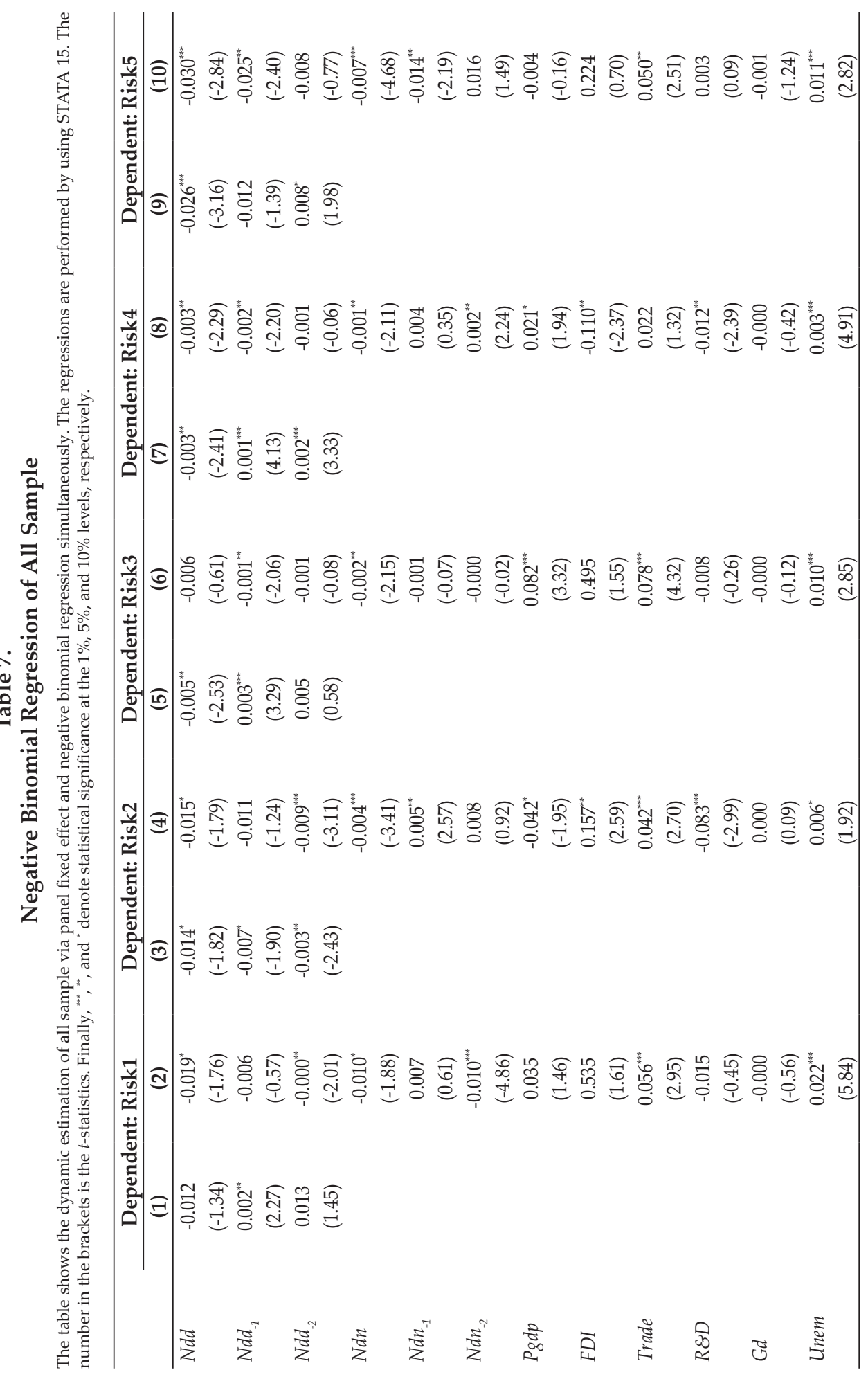




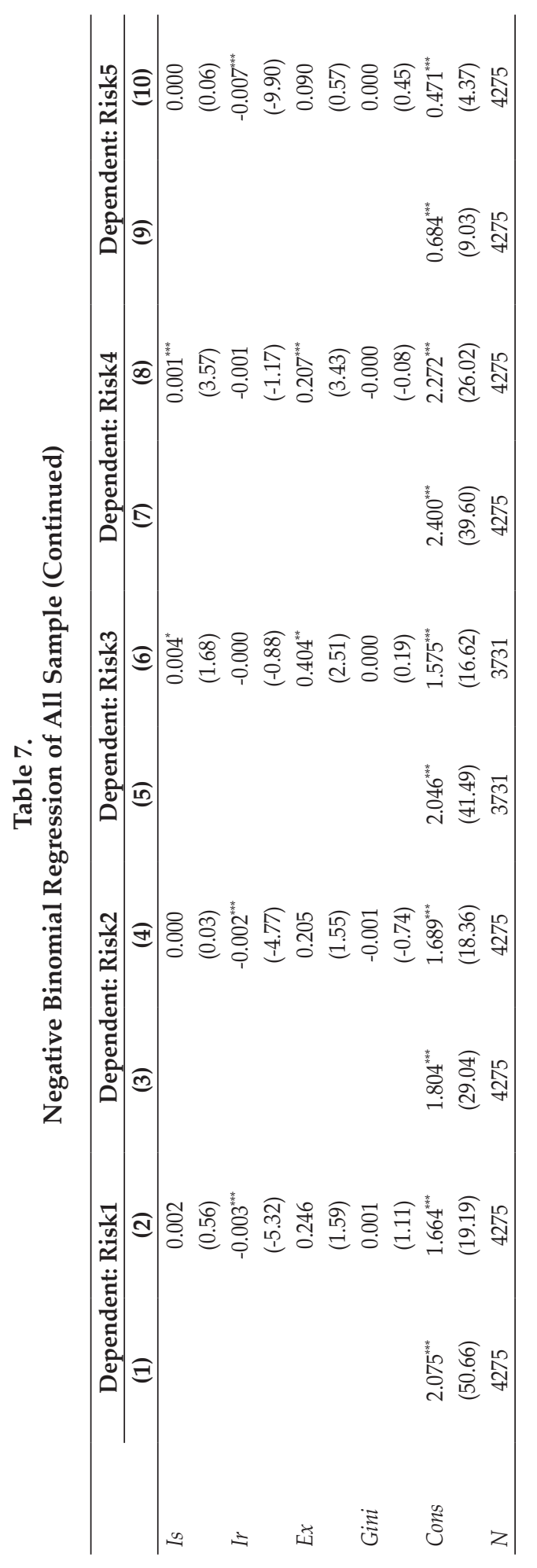




\section{D.2. Negative Binomial Regression}

Table 7 uses panel fixed effects regression that considers a negative binomial to test the model. We also reach the same conclusion, that $N d d$ has a significantly negative effect on different financial risks, except for Models (1) and (6). A long-run dynamic influence also exists, since the coefficients of $N d d_{-1}$ and $N d d_{-2}$ are almost significantly negative. The number of natural disasters affects different risks negatively for different numbers of lags, which also indicates a dynamic attribute.

\section{CONCLUSION}

Based on an unbalanced panel data of natural disasters and financial risks in 136 countries during 1984-2017, this study adopts a panel fixed effects model for parameter estimation for the entire sample and as classified by heterogeneity across country. We obtain the following main conclusions: (1) Natural disasters have strong negative effects on different financial risks, including foreign debt, debt service, exchange rate stability, the current account, and international liquidity. (2) The influences of natural disasters on financial risks are dynamic and long term; moreover, the negative effects weaken over time. (3) The negative effects of natural disasters on financial risks in OECD countries are weaker than those in non-OECD countries. Furthermore, natural disasters have a weaker influence in high-income countries than in low-income countries. High-income OECD countries are better able to cope with the destruction and loss brought about by natural disasters, in terms of higher levels of cooperation and better infrastructure and productivity.

Our research results will be helpful for policymakers in different countries. The key to decreasing financial risks is to prevent natural disasters, reduce the number of deaths and losses, establish reasonable financial systems, and so on. Hence the policy implications of this paper can be summarized in two aspects.

(1) The prevention of natural disasters. First, climate change is one of the major reasons behind natural disasters. Governments should introduce and improve pollution treatment technology to reduce the emission of greenhouse gases. Moreover, strict supervision over the illegal use of forests and grasslands can protect areas of vegetation, which can help reduce the damage of storms, landslides, floods, and so forth. Second, the government needs to establish better infrastructure and more stable houses in areas affected by frequent natural disasters. Dam construction can prevent floods and safe havens can reduce the number of deaths and loss from natural disasters. Finally, governments should speed up reconstruction after the occurrence of natural disasters. More supplies and aid should be provided for the affected and to rebuild factories.

(2) The establishment of a reasonable financial system. First, the country must improve its production technology to increase its GDP and revenue. More funds can be used to prevent natural disasters as the national economy improves, which can reduce domestic and foreign debt. Second, for low-income countries, an increase in the issuance of currency can solve short-term financial problems, but is unsuitable for the long term, since it can cause inflation. Therefore, countries need to improve people's confidence and increase investments to recover their production capacity as quickly as possible. Finally, increasing cooperation with other countries can be conducive to the disaster-affected country obtaining assistance, which will reduce pressure from domestic and foreign debt. Furthermore, cooperative countries 
will also supply the technologies and materials to aid in the recovery of the development of the disaster-affected country. Exports and imports will thus tend to be stable, and financial risks can be reduced.

\section{REFERENCES}

Abarcar, P., (2017) The Return Motivations of Legal Permanent Migrants, Evidence from Exchange Rate Shocks and Immigrants in Australia, Journal of Economic Behavior E Organization, 144, 62-77.

Ajide, K. B., and Raheem, I. D., (2016) The Institutional Quality Impact on Remittances in The ECOWAS Sub Region, African Development Review, 28, 462481.

Barone, G., and Mocetti, S., (2014) Natural Disasters, Growth and Institutions: A Tale of Two Earthquakes, Journal of Urban Economics, 84, 52-66.

Barthel, F., and Neumayer, E., (2012) A Trend Analysis of Normalized Insured Damage from Natural Disasters, Climatic Change, 113, 215-237.

Baur, D. G., Hong, K., and Lee, A. D., (2018) Bitcoin, Medium of Exchange or Speculative Assets?, Journal of International Financial Markets, Institutions and Money, 54, 177-189.

Bayoumi, T., Gagnon, J., and Saborowski, C., (2015) Official Financial Flows, Capital Mobility, and Global Imbalances, Journal of International Money and Finance, 52, 146-174.

Berrebi, C., and Ostwald, J., (2013) Exploiting The Chaos: Terrorist Target Choice Following Natural Disasters, Southern Economic Journal, 79, 793-811.

Breckner, M., Englmaier, F., Stowasser, T., and Sunde, U., (2016)., Resilience to Natural Disasters-Insurance Penetration, Institutions, and Disaster Types, Economics Letters, 148, 106-110.

Byoun, S., and Xu, Z., (2014) Contracts, Governance, and Country Risk in Project Finance, Theory and Evidence, Journal of Corporate Finance, 26, 124-144.

Cassar, A., Healy, A., and von Kessler, C., (2017) Trust, Risk, and Time Preferences After a Natural Disaster, Experimental Evidence from Thailand, World Development, 94, 90-105.

Cavallo, E., Galiani, S., Noy, I., and Pantano, J., (2013) Catastrophic Natural Disasters and Economic Growth, Review of Economics and Statistics, 95, 1549-1561.

Chiu, Y. B., and Lee, C. C., (2019) Financial Development, Income Inequality, and Country Risk, Journal of International Money and Finance, 93, 1-18.

Ebeke, C., and Combes, J. L., (2013) Do Remittances Dampen The Effect of Natural Disasters on Output Growth Volatility in Developing Countries?, Applied Economics, 45, 2241-2254.

Eckstein, Z., Setty, O., and Weiss, D., (2019) Financial Risk and Unemployment, International Economic Review, 60, 475-516.

Fang, Z., and Chang, Y., (2016) Energy, Human Capital and Economic Growth in Asia Pacific Countries-Evidence From A Panel Cointegration and Causality Analysis, Energy Economics, 56, 177-184.

Farhi, E., and Gabaix, X., (2015) Rare Disasters and Exchange Rates, The Quarterly Journal of Economics, 131, 1-52.

Fouejieu, A., (2017) Inflation Targeting and Financial Stability in Emerging Markets, Economic Modelling, 60, 51-70. 
Gourio, F., (2013) Credit Risk and Disaster Risk, American Economic Journal, Macroeconomics, 5, 1-34.

Hall, R. E., (2017) High Discounts and High Unemployment, American Economic Review, 107, 305-30.

Hallegatte, S., Green, C., Nicholls, R. J., and Corfee-Morlot, J., (2013) Future Flood Losses in Major Coastal Cities, Nature Climate Change, 3, 802.

Heger, M., Julca, A., and Paddison, O., (2008) Analysing The Impact of Natural Hazards in Small Economies: The Caribbean Case WIDER Working Paper Series, 115,3592-3597.

Holm, J. R., and Østergaard, C. R., (2015) Regional Employment Growth, Shocks and Regional Industrial Resilience: A Quantitative Analysis of the Danish ICT Sector Regional Studies, 49, 95-112.

Hoshi, T., (2018) Has Abenomics Succeeded in Raising Japan's Inward Foreign Direct Investment?, Asian Economic Policy Review, 13, 149-168.

Jonkman, S. N., and Kelman, I., (2005) An Analysis of the Causes and Circumstances of Flood Disaster Deaths, Disasters, 29, 75-97.

Kabisch, N., Frantzeskaki, N., and Pauleit, S., (2016) Nature-Based Solutions to Climate Change Mitigation and Adaptation in Urban Areas, Perspectives On Indicators, Knowledge Gaps, Barriers, And Opportunities for Action, Ecology and Society, 21, 39.

Kellenberg, D. K., and Mobarak, A. M., (2008) Does Rising Income Increase or Decrease Damage Risk from Natural Disasters?, Journal of Urban Economics, 63, 788-802.

Kilby, C., (2009) The Political Economy of Conditionality: An Empirical Analysis of World Bank Loan Disbursements, Journal of Development Economics, 89, 5161.

Kim, N., (2012) How Much More Exposed Are the Poor to Natural Disasters? Global and Regional Measurement, Disasters, 36, 195-211.

Klomp, J., (2017) Flooded with Debt, Journal of International Money and Finance, 73, 93-103.

Laséen, S., Pescatori, A., and Turunen, J., (2017) Systemic Risk: A New Trade-Off for Monetary Policy?, Journal of Financial Stability, 32, 70-85.

Li, L., Chen, J., Gao, H., and Xie, L., (2019) The Certification Effect of Government R\&D Subsidies on Innovative Entrepreneurial Firms' Access to Bank Finance, Evidence from China, Small Business Economics, 52, 241-259.

Liang, Y., Shi, K., Wang, L., and Xu, J., (2017) Local Government Debt and Firm Leverage: Evidence from China, Asian Economic Policy Review, 12, 210-232.

Miao, Q., and Popp, D., (2014) Necessity as The Mother of Invention: Innovative Responses to Natural Disasters, Journal of Environmental Economics and Management, 68, 280-295.

Mohan, P. S., Ouattara, B., and Strobl, E., (2018) Decomposing The Macroeconomic Effects of Natural Disasters: A National Income Accounting Perspective, Ecological Economics, 146, 1-9.

Niepmann, F., and Schmidt-Eisenlohr, T., (2017) International Trade, Risk and The Role of Banks, Journal of International Economics, 107, 111-126.

Ouattara, B., and Strobl, E., (2013) The Fiscal Implications of Hurricane Strikes in the Caribbean, Ecological Economics, 85, 105-115. 
Pek, S., Oh, C. H., and Rivera, J., (2018) MNC Foreign Investment and Industrial Disasters: The Moderating Role of Technological, Safety Management, and Philanthropic Capabilities, Strategic Management Journal, 39, 502-526.

Pesaran, M. H., (2007) A Simple Panel Unit Root Test in The Presence of CrossSection Dependence, Journal of Applied Econometrics, 22,265-312.

Raddatz, C., (2005) Are External Shocks Responsible For The Instability of Output in Low Income Countries?, The World Bank.

Reboredo, J. C., Rivera-Castro, M. A., and Ugolini, A., (2016) Downside and Upside Risk Spillovers Between Exchange Rates and Stock Prices, Journal of Banking $\mathcal{E}$ Finance, 62, 76-96.

Robinson, T. D., Oliveira, T. M., and Kayden, S., (2017) Factors Affecting the United Nations' Response to Natural Disasters: What Determines The Allocation of the Central Emergency Response Fund?, Disasters, 41, 631-648.

Sadorsky, P., (2014) The Effect of Urbanization On CO2 Emissions in Emerging Economies. Energy Economics, 41, 147-153.

Sawada, Y., and Takasaki, Y. (2017). Natural Disaster, Poverty, and Development: An Introduction, World Development, 94, 2-15.

Schettkat, R., (2010) Will Only An Earthquake Shake Up Economics?, International Labour Review, 149, 185-207.

Skoufias, E., (2003) Economic Crises and Natural Disasters: Coping Strategies and Policy Implications, World Development, 31, 1087-1102.

Song, M., Wang, S., and Sun, J. (2018). Environmental Regulations, Staff Quality, Green Technology, R\&D Efficiency, and Profit in Manufacturing, Technological Forecasting and Social Change, 133, 1-14.

Strobl, E., (2012) The Economic Growth Impact of Natural Disasters in Developing Countries: Evidence from Hurricane Strikes in The Central American and Caribbean Regions, Journal of Development Economics, 97, 130-141.

Toya, H., and Skidmore, M., (2007) Economic Development and The Impacts of Natural Disasters, Economics Letters, 94, 20-25.

Toya, H., and Skidmore, M., (2014) Do Natural Disasters Enhance Societal Trust?. Kyklos, 67, 255-279.

Visser, H., Petersen, A. C., and Ligtvoet, W., (2014) On The Relation Between Weather-Related Disaster Impacts, Vulnerability and Climate Change, Climatic Change, 125, 461-477.

Waldenberger, F., (2013) Confronting Earthquake Risk in Japan-Are Private Households Underinsured?, Asia Europe Journal, 11, 79-91.

Ward, P. S., Ortega, D. L., Spielman, D. J., Kumar, and N., Minocha, S., (2020) Demand for Complementary Financial and Technological Tools for Managing Drought Risk, Economic Development and Cultural Change, 68, 000-000.

Ward, P. S., and Shively, G. E., (2017) Disaster Risk, Social Vulnerability, and Economic Development, Disasters, 41, 324-351.

Wei,W.,Zhang,W.L.,Wen,J., and Wang,J.S.,(2019)TFPGrowthin ChineseCities: The Role of Factor-Intensity and Industrial Agglomeration, Economic Modelling, 2019. Yamamura, E., (2014) Impact of Natural Disaster on Public Sector Corruption, Public Choice, 161, 385-405.

Zhang, D., Cao, H., and Zou, P., (2016) Exuberance in China's Renewable Energy Investment: Rationality, Capital Structure and Implications With Firm Level Evidence, Energy Policy, 95, 468-478. 